\title{
Modelling intermodal travel in Switzerland \\ A recursive logit approach
}

\section{Working Paper}

Author(s):

Meyer de Freitas, Lucas (D); Becker, Henrik; Zimmermann, Maëlle; Axhausen, Kay W. (D)

Publication date:

2018-09

Permanent link:

https://doi.org/10.3929/ethz-b-000286496

Rights / license:

In Copyright - Non-Commercial Use Permitted

Originally published in:

Arbeitsberichte Verkehrs- und Raumplanung 1379 


\title{
Modelling intermodal travel in Switzerland:
}

\section{a recursive logit approach}

\author{
Lucas Meyer de Freitas ${ }^{\text {a }}$; Henrik Becker ${ }^{\text {a,*; }}$ Maëlle Zimmermann ${ }^{\text {b,c }}$; Kay W. Axhausen ${ }^{\text {a }}$ \\ *Corresponding Author: henrik.becker@ivt.ethz.ch \\ a Institute for Transport Planning and Systems, \\ ETH Zurich, Zurich, Switzerland \\ ${ }^{\mathrm{b}}$ Department of Computer Science and Operations Research, \\ Université de Montréal, QC, Canada \\ ${ }^{\mathrm{c}}$ CIRRELT - Interuniversity Research Centre on Enterprise Networks, Logistics and \\ Transportation, Montréal, QC, Canada
}

\begin{abstract}
We use data from the Swiss national household travel survey to 1. analyse the socioeconomic determinants for intermodal travel in Switzerland and 2. estimate a first large-scale multimodal recursive logit route choice model for urban trip making. We show that intermodal travel is mostly associated with ownership of transit subscriptions, which allow free at the point-of-use public transportation. We also present a framework using open-source data to generate the multimodal network for the recursive logit model estimation. The fact that the model only needs a multimodal network to model the transport supply makes it independent of path sampling algorithms for the choice-set construction and it thus provides an alternative to classic mode and route choice models, since it can estimate mode and route choice parameters with directly observed routes, removing the sampling bias. By eliminating the need to sample alternative paths for estimation, it also simplifies the estimation process, making it a viable choice as an integral solution for joint route and mode choice modelling.
\end{abstract}

\section{Keywords}

Intermodal travel; multimodal network; mode choice; route choice; recursive logit

\section{Highlights}

- Analysis of intermodal trip making in Switzerland.

- Estimation of the first multimodal recursive logit route choice model

- Simple methodology to construct a multimodal network based on open-source data.

- We show that the multimodal recursive logit model can be a useful tool for transport planning in urban areas. 


\section{Introduction}

Intermodal travel is the combination of different transport modes within the same path (Nobis, 2010). In this this paper, the word multimodal is used to describe a transport supply in the form of a multimodal network. It focusses on modelling intermodal trip making on such multimodal networks.

By travelling in an intermodal manner, transport infrastructures can be used more economically by redistributing flows (Spickermann et al., 2014; van Nes and Bovy, 2004; da Silva et al., 2009; Schade et al., 2011, Rode and Cruz, 2018). Given the near saturation of transport infrastructures in many cities across the world, combined with rising population densities, it comes as no surprise that intermodal travel is a subject of interest - not only in the academic field, but also in urban transport policy (Berlin, 2017; Munich, 2018). At the same time, mobility patterns are becoming more individualized and diffused (Klinger, 2017) leading to increased intermodal trip making and adaptive behaviour to meet mobility needs (Kuhnminhof et al., 2012, Rode et al., 2015).

To evaluate trade-offs between different trip stages of intermodal trip making, it is necessary to analyse not only mode, but also route choice behaviour. So far, modelling approaches encompassing both aspects on multimodal networks have been rare. Route choice models tend to focus on unimodal paths, while mode choice models do not consider the route in its detail. At the same time, route and mode decisions cannot be divided in the choice process, especially for intermodal trips. The increasing share of new modal combinations in the urban context, such as ride-hailing and shared mobility, further increase the share of intermodal travel (Spickermann et al., 2014). A tool allowing the modelling of mode and route choice decisions jointly becomes even more important in this context.

In the search for such a tool, we explore the suitability of the recursive logit model for intermodal urban travel demand analysis. Originally presented by Fosgerau et al. (2013), the model allows for an explicit representation of intermodal paths in a multimodal graph since the model does not require the generation of a choice-set, making of it an excellent candidate for the analysis of intermodal trip making. We use observations of different modes to evaluate the model's suitability as a comprehensive solution, allowing for trade-off estimation: not only for intermodal, but also for all trips within a multimodal network. Besides applying this model for the city of Zurich, we also analyse intermodal trip making in Switzerland, based on the latest Swiss mobility microcensus (BFS, 2017). For this, we make use of a binary logit regression to find the most important socioeconomic determinants for intermodal trip making.

The remainder of this paper is structured as follows: Section 2 provides a literature review on intermodal trip making (2.1) and multimodal route choice modelling (2.2). The recursive logit model is then formally presented in Section 2.3. Section 3 presents the Swiss microcensus data used in the remainder of the paper. Section 4 presents findings on intermodal trip making in Switzerland. In Section 5, construction of the multimodal network is introduced and in Section 
6 , results of model estimations using this network are presented. Section 7 ends with a discussion.

\section{Background}

The relevant literature of the two main topics of this paper are: intermodal trip behaviour and multimodal route choice modelling. After introducing relevant literature on these topics, we conclude the chapter by introducing the recursive logit model.

\subsection{Intermodal trip making}

Increased interest in intermodal travel is reflected by a growing body of literature on this behaviour's determinants. Krygsman and Dijst (2001) use the Dutch national travel survey to perform a binary regression analysing the determinants of multimodal travel. Jarass and Oostendorp (2017) make use of a household travel survey in Berlin to analyse the characteristics of intermodal travellers in the city. Miramontes et al. (2017) evaluate surveys with users of mobility stations in Munich to find the motivations for intermodal trips through the stations. Molin et al. (2016) perform a latent cluster analysis to identify multimodal travel groups in The Netherlands and Claus and Döppe (2016) evaluate affective determinants of intermodal travel. Blumenberg and Pierce (2012) use data from the U.S. National Household Travel Survey to compare the intermodal behaviour of low and high-income groups.

There are varying definitions of what constitutes an intermodal trip, depending on which modes are included in the definition. Some authors include walking as an independent mode only if the walking time is above a certain threshold (Diaz Olvera et al., 2014; Krygsman and Dijst, 2001), since walking is - strictly speaking - part of any trip. Transit can be viewed as one unique mode, or different transit modes can be viewed as separate modes. There is no consensus in literature about definition of these thresholds. Regardless of definition, intermodal trips are more burdensome than unimodal ones (Chlond, 2013; Krygsman, 2004; Claus and Döppe, 2016). This higher burden comes from the fact that intermodal travel is associated with more planning and physical effort by the traveller. Intermodal travel thus requires flexibility and openness, as well as the willingness to travel with a lower degree of comfort compared to individual motorized travel, which is flexible and can fulfil almost all mobility needs (Groth, 2016). The need to transfer between modes is a large share of this burden, given its inconvenience and the uncertainty associated with it (Yoo, 2015; Jang, 2010; Guo and Wilson, 2004, Iseki et al., 2006). This inconvenience and uncertainty is more important when switching from individual modes to transit modes since waiting times due to transit services irregularities are out of the traveller's control.

This lack of control over one's movement, resulting from dependence on external conditions, is perceived as stressful and inconvenient (Claus and Döppe, 2016). For this reason, public modes are perceived as especially inconvenient by many travellers. The navigation through a transit network map alone can reach cognitive limits, thus adding mental weight to the trip 
(Galotti et al., 2016). Although public transport adds burdens to travel, the share of intermodal trips is positively correlated with the number of supplied transit trips within a region (Galotti and Barthelemy, 2014). This results from the higher frequencies and better spatial coverage of transit systems in urban, as opposed to rural areas. Still, the extent of the effort needed to conduct intermodal trips depends on intermodal travellers' socio-economic characteristics.

Younger individuals tend to switch more often between transport modes within a trip than older travellers (Jarass and Oosterndorp, 2017; Nobis, 2010). This is related to the higher flexibility of the members of the first group and necessity on the other; young people are often in education, or have no driving license. The effects of income are ambiguous in the literature. Blumenberg and Pierce (2012), Miramontes et al. (2017), Nobis (2010) and Krygsman and Dijst (2001) find that higher income individuals are more intermodal than lower income ones. Jarass and Oostendorp (2017) do not find substantial income differences between groups. Education, often correlated to income, has positive effects on intermodal travel (Claus and Döppe, 2016; Kuhnimhof et al. 2012; Miramontes et al. 2012; Jarass and Oostendorp, 2017). Women take more intermodal trips than men (Krygsman and Dijst, 2001; Jarass and Oosterndorp, 2017; Olafsson et al., 2016). They are known to be more transit-oriented and flexible in their mobility behaviour (Polk, 2004), a fact related to lower purchasing power and women's lower car ownership. Household size influence is also variable. Krygsman and Dijst (2001) find that smaller households are more intermodal. Jarass and Oostendorp (2017), find that this holds for all trips, except those including bike stages, where larger households have higher shares of intermodal trips. An increased household size usually results of having children and households with children are associated with car-oriented mobility culture and a decrease in transit share (Klinger, 2017; Nobis, 2010). Intermodal travellers can thus be characterized as urban, young, female, well-educated and childless. This group does not travel in an intermodal manner out of necessity; given their flexibility, they adapt travel modes to different stages to optimize travel times in an urban network (Franke, 2004). Intermodal travellers are also associated with two key perceptual characteristics of users combining new travel modes such as sharing and ride-hailing users: individuality and innovation (Claus and Döppe, 2016).

Findings from the literature presented above focus on multimodal travellers' socioeconomic characteristics and attitudes. While results of these studies provide valuable insights into personal intermodal travel determinants, policy making and infrastructure planning also require evaluation of trade-offs between different travel options at a trip level. Multimodal route choice models are best suited for this task, since they can model an intermodal trip in an integrated manner, allowing us to capture trade-offs between different modes compromising an intermodal trip and traveller perceptions of different trip stages. We can thus identify relevant urban network attributes for intermodal trip making, like transit service characteristics or transfer facilities. Besides serving as an evaluation tool for planning, these model results are also valuable inputs for intermodal trip planning applications, which play an important role in intermodal travel promotion (Zhang et al., 2012). 


\subsection{Multimodal route choice modelling}

Stated preference (SP) methods have been employed to estimate trade-offs for intermodal travel (Arentze et al., 2013), but are not suited for modelling intermodal route choice in a multimodal network because of numerous possible alternative combinations and the resulting high response burden. Furthermore, SP methods can produce biased results emerging from framing effects (Beck et al., 2017; Ojeda-Cabral et al. 2018), since the respondent is not experiencing the trip himself.

Revealed preference (RP) multimodal route choice models are rare. To our knowledge, Hoongedoorn-Lanser (2005) and Fiorenzo-Catalano (2007) were the first to address this topic. Hoongedoorn-Lanser (2005) uses path size and C-logit route choice models for long-distance trips, e.g. the Dordrecht-Leiden urban corridor in The Netherlands, including access/egress and feeder modes. A branch and bound algorithm is used to generate choice sets on a diachronic supernetwork. However, the path sampling process is very complex and cumbersome. It is based on observations stemming from extensive in-depth interviews conducted in intercity trains. Fiorenzo-Catalano (2007) uses the same data as Hoongedoorn-Lanser (2005), but focuses on the development of choice-set generation algorithms for multimodal networks.

Both authors use a hub-and-spoke network: possibly useful for long distance travel situations, but a hurdle when analysing urban travel with the higher number of alternative paths within an urban network. Rieser-Schüssler et al. (2014) develop a branch and bound algorithm for path sampling in urban transit networks. Montini et al. (2017) use this algorithm for sampling transit routes for a multimodal route choice model and a BFS-LE algorithm is used for the sampling of individual paths. The use of two different algorithms for path sampling for model estimation results in a lack of consistency and makes it impossible to sample intermodal paths. The resulting choice sets are combined as alternatives for estimation of a MNL model with path size adjustment for GPS tracked paths in Zurich. Zimmermann et al. (2018) make use of the same dataset to estimate a recursive logit model just for transit trips. Her model accounts for transfers between different modes, but does not include a street layer for the representation of access and egress modes. Eluru et al. (2012) estimate a mixed multinomial route choice model from information collected on usual commute patterns of students in Montreal, also accounting only for transit trip stages of train, metro and bus modes. Anderson et al. (2017) estimate a multimodal route choice model on Copenhagen, using observations from a household travel survey to estimate route choice models in a transit network with walking access and egress, but employing only searches for paths within the transit network. While Anderson et al. (2017) and Montini et al. (2017) make use of detailed diachronic transit networks to generate choice sets within feasible time and route constraints, the first lacks a street network embedding and the second lacks a uniform choice set generation algorithm across all modes. Table 1 summarizes the studies presented above. 


\begin{tabular}{lllll} 
Study & Network & Modes & $\begin{array}{l}\text { Intermodal } \\
\text { path } \\
\text { sampling }\end{array}$ & Goal \\
\hline $\begin{array}{l}\text { Hoongedoorn-Lanser (2005) } \\
\text { and Fiorenzo-Catalano (2007) }\end{array}$ & $\begin{array}{l}\text { Diachronic } \\
\text { transit Hub-and- } \\
\text { spoke }\end{array}$ & $\begin{array}{l}\text { Transit, car, } \\
\text { access/egress }\end{array}$ & Yes & $\begin{array}{l}\text { Interurban } \\
\text { multimodal } \\
\text { travel }\end{array}$ \\
\hline & $\begin{array}{l}\text { Transit, car, } \\
\text { bike and } \\
\text { transit }\end{array}$ & $\begin{array}{l}\text { Partly } \\
\text { (transit only) }\end{array}$ & $\begin{array}{l}\text { Urban } \\
\text { multimodal } \\
\text { travel }\end{array}$ \\
\hline & $\begin{array}{l}\text { Diachronic } \\
\text { transit }+ \text { urban } \\
\text { street }\end{array}$ & $\begin{array}{l}\text { Transit with } \\
\text { access/egress }\end{array}$ & $\begin{array}{l}\text { Partly } \\
\text { (transit only) }\end{array}$ & $\begin{array}{l}\text { Urban transit } \\
\text { route choice }\end{array}$ \\
\hline Anderson et al. (2017) & $\begin{array}{l}\text { Diachronic } \\
\text { transit }\end{array}$ & Transit & Not needed & $\begin{array}{l}\text { Urban transit } \\
\text { route choice }\end{array}$ \\
\hline Zimmermann et al. (2018) & Static transit + & Transit, car, \\
urban street & walk, bike & Not needed & $\begin{array}{l}\text { Urban } \\
\text { travel }\end{array}$ \\
\hline
\end{tabular}

All models except Zimmermann's (2018) model in Table 1 require the generation of a choice set, a non-trivial task. It has been shown that misspecifications in choice-set generation can bias model parameters in mode choice models (Williams and Ortuzar, 1982), as well as in route choice models (Bovy, 2009; Prato, 2009; Frejinger et al., 2009), although this issue is much more problematic in route choice models. In mode choice modelling, the decision-maker usually knows alternatives well, but in a route-choice situation, the alternatives are not known to the decision-maker nor to the modeller (Prato, 2009). Routes must thus be sampled from an underlying network with thousands of feasible alternatives. Choice set generation is needed because conventional path choice models compare utility of a chosen path against that of alternative paths. This task is especially challenging in multimodal networks, since a relevant set of paths, containing various stage combinations of different modes, is needed.

Stern and Leiser (1988) show that transit riders do not usually take more than 3 alternative routes into account and one third of intercity travellers surveyed by Hoongedoorn-Lanser (2005) do not even consider an alternative. It has also been shown that, for routine trips, mobility patterns and route choice behaviour are extremely regular (Lanzendorf, 2003; Lima et al., 2016; Levinson and Zhu, 2013), resulting in low variance in route choice and few considered alternatives. At the same time, variance is needed to consistently estimate a discrete choice model. Problematically, generating multiple distinct alternatives for multimodal trips is very challenging with traditional path sampling algorithms. The studies listed in Table 1 use complex path sampling methods refined for urban transit networks to generate choice sets, obtaining an average of 30 to 50 alternative routes. Eluru et al. 2012 obviates this difficulty by generating between 4 and 6 alternative paths via Google Maps. In each of these studies, the mismatch between an individual's and the modelled choice set, as well as the sampling algorithm used for choice set generation, may cause biased parameters in route choice models. 


\section{Figure $1 \quad$ Notation}

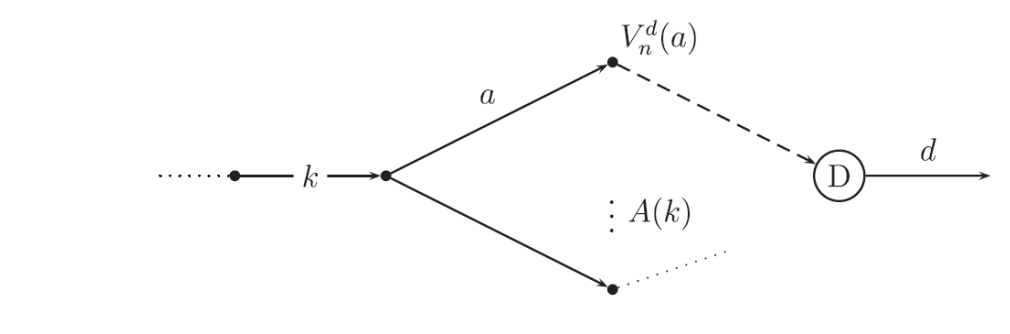

Adapted from Fosgerau et al. (2013)

The recursive logit (RL) model removes this bias by breaking path choice down to a sequential selection of links, eliminating the need for path sampling and the bias created by this procedure. The model is effectively a link choice model corresponding to a path choice model with infinite choice set (Fosgerau et al., 2013). By removing the choice set generation step, it also simplifies route choice modelling, since the only inputs needed for model estimation are: 1. a network graph in the form of a link-list and; 2. path observations in the form of a sequence of link ID's. Applications of the model on car, bike and transit networks have shown that the approach allows consistent modelling of unimodal route-choice behaviour (Fosgerau et al. 2013; Mai et al. 2015a; Zimmermann et al. 2017). The approach has not yet been used for the estimation of trade-offs between different modes on a multimodal network nor for intermodal paths.

\subsection{The recursive logit model}

This section is based on the recursive logit model as first presented by Fosgerau et al. (2013). Instead of evaluating the choice of one path among all other possible paths, the approach recursively models, for each visited link $k$, the conditional choice probability of the next link $a$ among the set of outgoing links $A(k)$, given the destination. This choice is modelled until the path destination node $\mathrm{D}$, represented in the model by a virtual destination link $d$, is visited.

For an individual $n$ travelling in the network the instantaneous utility of link $a$ conditional on link $k$ is given by:

$u_{n}(a \mid k)=v_{n}(a \mid k)+\varepsilon_{n}(a)$

with the random term $\varepsilon(a)$ being i.i.d. extreme value type 1 with zero mean. The complete utility of link $a$ is the sum of the instantaneous utility and the expected maximum utility to destination $d$, given by the Bellman equation:

$\frac{1}{\mu} \mathrm{V}_{\mathrm{n}}^{\mathrm{d}}(\mathrm{k})=\mathbf{E}\left[\max _{\mathrm{a} \in \mathrm{A}(\mathrm{k})}\left(\mathrm{V}_{\mathrm{n}}(\mathrm{a} \mid \mathrm{k})+\mathrm{V}_{\mathrm{n}}^{\mathrm{d}}(\mathrm{a})+\varepsilon(\mathrm{a})\right)\right] \forall \mathrm{k} \in \mathrm{A}$ 
5 To calculate the probability above, one needs to solve the value function $V_{n}^{d}(k)$ at link $k$, given

The choice of link $a \in A(k)$ is made so that the total utility $u_{n}(a \mid k)+\mathrm{V}_{\mathrm{n}}^{\mathrm{d}}(\mathrm{a})$ is maximized. The probability of choosing a link $a$ conditional on current link $k$ and destination link $d$ is given by the multinomial logit model:

$$
P_{n}^{d}(a \mid k)=\frac{e^{\frac{1}{\mu}\left(v_{n}(a \mid k)+v_{n}^{d}(a)\right)}}{\sum_{a^{\prime} \in A(k)} e^{\frac{1}{(\mu}\left(v_{n}\left(a^{\prime} \mid k\right)+v_{n}^{d}\left(a^{\prime}\right)\right)}}
$$

\section{by (1). This function represents the expected maximum utility from link $k$ to the targeted} destination $d$. It can also be expressed by the following logsum:

$$
V_{n}^{d}(k)=\mu \ln \sum_{a^{\prime} \in A(k)} e^{\frac{1}{\mu}\left(v_{n}(a \mid k)+V_{n}^{d}(a)\right)}
$$

In order to solve the system above, the equation is written in matrix form so that a system of linear equations can be solved. For this, it is assumed that $\mathbf{M}(|\hat{\mathrm{A}}| \mathrm{x}|\hat{\mathrm{A}}|)$ is an incidence matrix which defines instantaneous utilities for all link pairs in the network.

$$
M_{k a}=\left\{\begin{array}{cc}
e^{\frac{1}{\mu} V_{n}(a \mid k)} & a \in A(k) \\
0 & \text { otherwise }
\end{array}\right.
$$

$\mathbf{M}$ has a zero row for each $k=d$. Let $\mathbf{z}(|\hat{\mathrm{A}}| \mathrm{x} 1)$ be a vector with elements $\mathbf{z}_{\mathbf{k}}=\mathrm{e}^{\frac{1}{\mu} \mathrm{v}(\mathrm{k})}$ and let $\mathbf{b}(|\hat{\mathrm{A}}| \mathrm{x} 1)$ be a vector with elements $\mathrm{b}_{\mathrm{k}}=0, \mathrm{k} \neq \mathrm{d}$ and $\mathrm{b}_{\mathrm{d}}=1$ for $k=d$. The system of linear equations becomes:

$$
(\mathbf{I}-\mathbf{M}) \mathbf{z}=\mathbf{b}
$$

with $\mathbf{I}$ being the identity matrix. If $\mathbf{I}-\mathbf{M}$ is invertible, the system allows us to calculate the value function $V_{n}^{d}(k)$ for each destination using only instantaneous utilities for all links in the network. If no personal attributes of traveller $n$ are included in the model, it is also necessary to calculate the instantaneous utilities - and therefore the value function - only once per interaction of the optimization algorithm. The calculations associated with this can become computationally very expensive. Furthermore, the computation time increases exponentially for larger networks, since large inverse matrices must be calculated.

The probability of choosing a path $\sigma$, representing a sequence of links $\left(\mathrm{k}_{0} \ldots \mathrm{k}_{\mathrm{I}}\right)$ with $\mathrm{k}_{\mathrm{i}+1} \in$ $A(k)$, is given by the Markov property of the model:

$$
P_{n}^{d}(\sigma)=\prod_{i=0}^{\mathrm{l}-1} \mathrm{P}\left(\mathrm{k}_{\mathrm{i}+1} \mid \mathrm{k}_{\mathrm{j}}\right)=\frac{\mathrm{e}^{\frac{1}{\mathrm{\mu} v(\sigma)}}}{\mathrm{e}^{\frac{1}{\mu} \mathrm{v} d\left(\mathrm{k}_{0}\right)}}
$$


Where $\mathrm{v}(\sigma)=\sum_{\mathrm{i}}^{\mathrm{I}-1} \mathrm{v}\left(\mathrm{k}_{\mathrm{i}+1} \mid \mathrm{k}_{\mathrm{j}}\right)$ is the deterministic part of the utility of the path. The value function $V^{d}\left(\mathrm{k}_{0}\right)$ corresponds to the expected maximum utility of all possible paths from an origin $\mathrm{k}_{0}$ to a destination $\mathrm{d}$. Therefore, the choice probability for a single path collapses to a path based MNL model with an infinite, but discrete choice set of all paths originating from $\mathrm{k}_{0}$, denoted $\Omega\left(\mathrm{k}_{0}\right)$ :

$$
\mathrm{P}_{\mathrm{n}}^{\mathrm{d}}(\sigma)=\frac{\mathrm{e}^{\frac{1}{\mu} \mathrm{v}(\sigma)}}{\sum_{\sigma \in \Omega\left(\mathrm{k}_{0}\right)} \mathrm{e}^{\frac{1}{\mu} \mathrm{v}\left(\mathrm{k}_{0}\right)}}
$$

\section{Data}

Data used for this study stems from the Swiss mobility microcensus 2015 (BFS and ARE, 2017), a household travel survey of the Swiss population, conducted every five years. The data is collected through computer-assisted telephone interviews, where individuals are asked about socio-demographic characteristics, ownership of mobility tools (car, transit tickets), attitudes about mobility and transport policies, irregular mobility behaviour (trips with overnight stays, day trips), as well as their daily mobility behaviour. Data about the latter, as well as travellers' socioeconomic data, is used in this study. The daily mobility behaviour is based on a reference day, randomly determined for each individual. Each respondent was contacted within 2 days and asked to respond a detailed questionnaire about the trips conducted during the reference day, for a period from January 2015 until February 2016.

The population sampled for the 2015 study consists of 57'090 individuals from around the country (BFS, 2018). In the city of Zurich, 4'272 individuals participated in the interview, a sample of $1 \%$ of the population. The travel survey has one special characteristic; it is stagebased. Respondents are asked about each individual stage within each trip, which is particularly interesting for intermodal travel analysis. The interviewed individuals travelled a total of 193'880 trips, divided into 279'173 stages. Very short walk stages were excluded. The average number of stages is 1.04 per trip when the main mode is an individual mode and 3.54 when the main mode is a collective mode. For trips over five kilometers with car as the main-mode, respondents are also asked about waypoints passed en-route, to ensure a more realistic routing of the actual stage.

\section{Intermodal trip making in Switzerland}

As far as we know, no systematic analysis of intermodal trip making in Switzerland has yet been conducted. Given that intermodal trip making can be defined in different ways, we base our analysis on these two: Intermodal trips - in a broad definition - are all trips consisting of more than two stages and at least two different travel modes, regardless of which mode combinations are reported. A strict definition, on the other hand, excludes all combinations 
constituted by the walk-transit-walk scheme and the walk-car-walk scheme. As in other studies, intermodal travel mostly has transit as the main travel mode, regardless of definition (Table 2).

Table 2

Mode shares by intermodal trip definition (microcensus 2015 trips)

\begin{tabular}{lrrr} 
Trip main mode & Broad & Strict & All trips \\
\hline Slow & $3.4 \%$ & $13.3 \%$ & $32.5 \%$ \\
Individual motorized & $34.1 \%$ & $22.7 \%$ & $54.6 \%$ \\
Transit & $62.4 \%$ & $64.0 \%$ & $12.9 \%$ \\
Share of total observations & $20.5 \%$ & $3.4 \%$ & $100 \%$ \\
\hline
\end{tabular}

$20.5 \%$ of all paths in the microcensus fit the broad definition, while $3.4 \%$ fit the strict definition. These values are very similar to those found by Jarass and Oostendorp (2017) for intermodal travel in Berlin. The main trip mode shows that intermodal travel is transit-based. At the same time, intermodal travel, strictly defined, is more often based on slow modes than in the broad definition, because trip purposes for strict intermodal travel are more often leisure and less often shopping trips ( $40 \%$ vs. $37 \%$ and $8 \%$ vs. $12 \%$, respectively). Travellers are usually willing to put more effort into travelling for leisure than for other trip purposes, while the inverse is the case for shopping trips, since the need to carry shopping bags reduces the traveller's flexibility.

Main path structures of multimodal trips in a broad definition are: walk - bus - walk (8'664 counts), followed by walk - heavy rail - walk (4'655 counts). Multimodal trips in a strict definition are dominated by the bike - heavy rail - walk structure (375 counts) and car as a passenger - heavy rail - walk (291 counts) trip structures. To gain insight into the socioeconomic determinants of intermodal travel, we conduct a binary logit regression on intermodal travel. The dependent variable is 1 if the individual conducted at least one intermodal trip during his/her reference day and 0 otherwise. Regressions are estimated for both definitions of intermodal travel. We restrict our observations to adult individuals since there are too few observations of minors.

Urban structure of residence parameters show that denser urban agglomerations have more intermodal trips. This implies that Galloti and Barthelemy's findings (2014) hold for Switzerland, arguably because agglomerations have more transit services. The results show that not only access to a good transit supply, but also seamless access to transit, in the form of mobility tool ownership, are important. Transit subscriptions, allowing for free travel within the country (for example, the $\mathrm{GA}^{1}$ ) or a region (in the case of a regional subscription), are the

\footnotetext{
${ }^{1}$ The GA is a travelcard which can be purchased from the Swiss Federal Railways for around 3800 USD and gives access to all public transit (both urban and long distance) within Switzerland for a year. Regional travelcards give access to public transit within a certain region. The halbtax is a yearly 180 USD subscription which gives a $50 \%$ discount on train tickets and about $30 \%$ on local transit tickets.
} 
1 single most important factors driving intermodal trip making (see Becker et al., 2017 for a

2 comprehensive model of mobility tool ownership in Switzerland).

\begin{tabular}{lrrrrrr} 
& \multicolumn{3}{c}{ Intermodal Broad } & & \multicolumn{3}{c}{ Intermodal Strict } \\
Parameter & Estimate & $\mathrm{t}$-test & & Estimate & $\mathrm{t}$-test \\
\hline Intercept & -0.624 & -11.033 & $* * *$ & -2.947 & -40.931 & $* * *$ \\
Male & -0.179 & -7.285 & $* * *$ & -0.087 & -2.124 & $*$ \\
Average daily trip distance $(\mathrm{km})$ & 0.008 & 17.602 & $* * *$ & 0.014 & 27.821 & $* * *$ \\
GA transit subscription & 1.455 & 32.854 & $* * *$ & 1.292 & 21.310 & $* * *$ \\
Regional transit subscription & 1.476 & 38.294 & $* * *$ & 0.706 & 12.322 & $* * *$ \\
Half-tax subscription & 0.253 & 9.455 & $* * *$ & 0.417 & 9.050 & $* * *$ \\
Car available & -0.319 & -10.618 & $* * *$ & -0.272 & -5.726 & $* * *$ \\
Bike available & -0.154 & -5.541 & $* *$ & 0.235 & 4.754 & $* * *$ \\
High school diploma & 0.225 & 7.665 & $* * *$ & 0.168 & 3.641 & $* * *$
\end{tabular}

\section{Household Size}

1 Person - Reference

2 Persons

$\begin{array}{lll}-0.097 & -2.699 & * * \\ -0.115 & -2.658 & * * \\ -0.209 & -4.941 & * * * \\ -0.295 & -5.590 & * * *\end{array}$

Age

18-30 - Reference

$30-45$

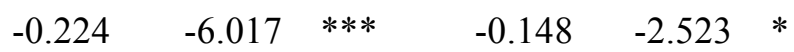

45-64

$-0.324$

$-9.237 * * *$

$-0.192 \quad-3.454 \quad * * *$

$64+$

$-0.353$

$-7.967$

$-0.310-4.278 * * *$

\section{Urban structure of residence location}

Rural community - Reference

Isolated city

$0.195 \quad 5.692$

Suburb of urban agglomeration

$0.197 \quad 4.620 \quad * * *$

Core of urban agglomeration

0.290

8.236

McFadden $\mathrm{R}^{2}$

0.359

0.348

Observations

$34^{\prime} 372$

$34^{\prime} 372$

Sign. codes: $0 * * * 0.001 * * 0.01 * 0.05$

- Some variables were removed from the estimation of strict models because of the statistical insignificance of the estimates 
The ownership of car and bike are also explanatory factors for multimodal travel. Car owners tend to have a rather unimodal travel behaviour (Heinen and Chatterjee, 2015), as also reflected in our findings. While possession of car and bike have a negative effect on intermodal travel in a broad definition, bike ownership is associated with a higher share of multimodal trips, strictly defined. Both are very flexible transport modes allowing door-to-door (for short distances in the case of bikes) mobility, thus providing a highly attractive alternative to transit. The negative effect of bike ownership for intermodal travel - broadly defined - is reflected by the dominance of walking - as access and egress mode - to reach transit in the trip structure. Excluding this mode, as access to transit in the strict definition, results in a positive bike effect in intermodal trips. When excluding access and egress by walking, Jarass and Oostendoorp (2017) and Molin et al. (2016) also find a positive bike ownership effect on intermodal travel.

Intermodal travel is slightly more attractive for longer routes, especially for strict intermodal paths, a finding also shown by Krygsman and Dijst (2001). This is expected, since with increasing distance, individuals are willing to put more effort into trip planning and accept the physical effort and stress of switching between modes. This is reflected by the decreasing marginal value of travel time savings and value of transfer time with increasing trip distances (Weis et al., 2017). The fact that the effect is even more significant for intermodal trips in a strict definition corroborates the findings that individuals are more willing to incur more inconveniences for longer trips.

Males conduct less intermodal trips than females, which is a reflection of the car ownership gender gap. The microcensus data shows that $51 \%$ of women and $62 \%$ of men have access to a car, leading women to take more trips with transit as a main mode and more intermodal trips in general. Increasing age has a negative effect on intermodal travel, as does increasing household size. The correlation between household size and presence of children in the household is 0.77 , pointing towards a negative effect of children on the intermodal trip making of larger households. Income variables were tested in the models, but were found to be insignificant. We conclude that income is not a relevant variable for explaining intermodal travel behaviour in Switzerland, as also found by Jarass and Oostendorp (2017) in Berlin. The insignificance of household and residence location variables for the intermodal strict model might indicate that this travel behaviour is more related to affective attributes or lifestyles than to location characteristics.

Having identified the main socio-demographic determinants for intermodal travel in Switzerland, we will now study the effect of network attributes on intermodal trips.

\section{Generating a multimodal network for Zurich}

Estimating a recursive logit model is computationally expensive. We thus limit our analysis to the core urban area of the metropolitan area of Zurich (Figure 2). Since we are working with census data, it is necessary not only to construct a multimodal network, but also to route 
observations on the network. The Zurich network was constructed in multiple layers, using OSM data for the street network and GTFS data for the transit network. Network generation and observation routing for model estimation are described below.

\subsection{Street network}

The street network is based on the open-source OSM network, designed to be used as a navigation network, containing many small links representing network geometry. Since only topological network elements are needed to estimate a recursive logit model and a large network size not only increases computation time, but the presence of very small links also poses numerical issues for the optimization algorithm, the network is reduced to a topological one. The street network thus used to generate the multimodal network is the urban network of Zurich generated for the IVT 2015 MATSim baseline scenario (Bösch et al., 2016). For scenario generation, the authors apply an algorithm to the OSM network, which combines links smaller than $50 \mathrm{~m}$ and removes hiking trails and inaccessible forest roads from the network (insignificant for urban travel demand estimation). This algorithm reduces the network from $210^{\prime} 171$ links to $30^{\prime} 372$ links and $13^{\prime} 828$ nodes (Figure 2). For each individual transport mode, an individual layer of the network is created. Links representing car, bike and walk then have the same node pairs. Travel time values are calculated with a travel speed of $1.2 \mathrm{~m} / \mathrm{s}$ for walk and for bike, $3.2 \mathrm{~m} / \mathrm{s}$. These values are the first quartile of the microcensus average travel speeds for these modes in Zurich. For the walk and bike networks, motorways are also removed (ring road in Figure 2 - right).

Figure 2 OSM network for slow modes (left) and MATSim street network (right).

\subsection{Transit network}

The transit network is based on time-dependent schedule information: more specifically, opensource GTFS data for Zurich. While the multimodal route choice models reviewed in the literature make use of time-dependent transit networks, we simplify the network by 
transforming it into a static graph. This removes the possibility of modelling waiting times or transfer times, but given that the departure times in the microcensus observations are reported at 15 minute intervals and the average daily headway in the study area is 10.8 minutes, we assume this does not cause loss of information. Furthermore, in a high frequency transit network, such as the one in Zurich, transfer times are short and travellers do not base their travel decisions on headways, but rather on service reliability (Abkowitz et al., 1978). Lüthi, Weidmann and Nash (2007) furthermore show that the average waiting times for the first boarding are independent of headway in Zürich.

The static transit network is generated by creating a link for every unique combination of transit stop coordinates and transit modes in the published GTFS data schedules. Network nodes thus represent not only individual platforms but also distinct transit lines departing from each transit stop location. Link attributes are travel time and headway. Link travel times are calculated as the difference between the published arrival time at the downstream stop and departure time at the upstream stop and are then averaged across all runs. Some link travel times were null and had to be set to 1 minute; GTFS data consists of published schedules, which have the minute as smallest time unit and sometimes sequential stops have the same published departure time. The second link attribute is headway. While link travel times rarely vary across different schedules, headways do vary, since transit agencies adapt their supply during the day. We use headways during the morning peak hours as a link headway attribute. As almost half of the observations in the dataset occur during the morning or evening peak and the headways on most lines are not substantially increased in between ${ }^{2}$, this can be justified. Most bus and tram lines running in the inner city also have a constant headway of less than 10 minutes, a threshold under which a service can be classified as highly frequent and headways cease to be a significant factor for transit route choice decisions (Kimpel et al., 2000). The transit network consists of 10’298 transit links and 1'585 nodes.

At this point, the constructed transit network does not include links for transfers. Then, for each network node, a virtual transfer link is added to all nodes corresponding to a transit stop within a $400 \mathrm{~m}$ radius. This includes transfer links connecting the same stop, as in the case of distinct transit lines departing from different platforms within the same stop location, or even the same platform. 9'556 transit transfer links were created this way, resulting in a complete transit network with 19'854 links.

The full multimodal network, consisting of the street and transit network is created by connecting every transit stop to each street network node within a 50m radius, creating 19'302 multimodal transfer links. Figure 3 shows a detail of the final network around Zurich central station. The full multimodal network consists of $127^{\prime} 873$ links. This explicit representation of different modes becomes very practical for the modelling of different stages of intermodal trips, a challenging task with classic models (Hoongdoorn-Lanser, 2005). Table 4 shows attribute values for network links.

\footnotetext{
${ }^{2} 43 \%$ of transit lines even have the same headway during peak hours and midday off-peak hours.
} 


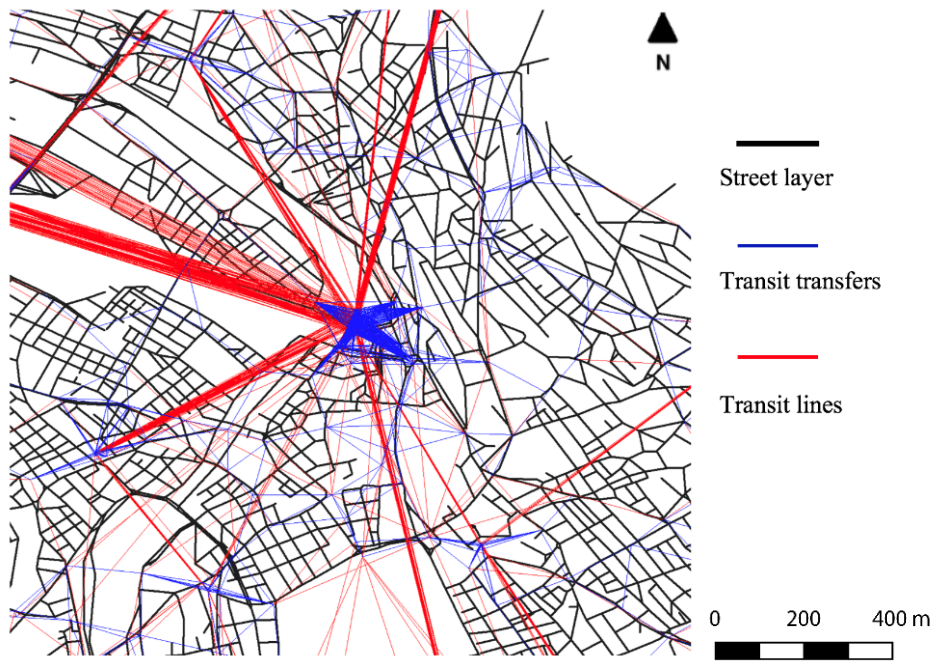

Table 4 Statistical summary of link attributes in minutes

\begin{tabular}{lllllll} 
& \multicolumn{3}{c}{ 1st } & & & 3rd \\
& Min. & Quantile & Median & Mean & Quantile & Max. \\
\hline Car travel time & 0.001 & 0.066 & 0.142 & 0.187 & 0.253 & 2.142 \\
Walk travel time & 0.013 & 0.559 & 1.079 & 1.454 & 1.907 & 17.220 \\
Bike travel time & 0.003 & 0.145 & 0.281 & 0.378 & 0.496 & 6.700 \\
Heavy rail travel time & 1.000 & 2.000 & 3.000 & 3.705 & 4.000 & 18.000 \\
Tram travel time & 1.000 & 1.000 & 1.000 & 1.493 & 2.000 & 4.000 \\
Bus travel time & 1.000 & 1.000 & 1.000 & 1.804 & 2.000 & 25.000 \\
Headway & 5.000 & 7.000 & 9.000 & 10.850 & 14.000 & 65.000 \\
\hline
\end{tabular}

\subsection{Routing of observations}

Microcensus observations are at stage level, containing start and end points, as well as information on the transport mode used in each stage. These had to be routed on the networks to obtain path observations. For the street-based modes, a modified version of the Graphhopper Directions API (Graphhopper, 2017) was used (Molloy et al., 2017). For transit network, the routing was performed with the Conveyal R5 router (Conveyal, 2017). Trip stages were read by a Java code, sending a routing request to the respective router based on the chosen mode. Transit routing requests are also differentiated by transit mode.

While the output from the Graphhopper router is already a sequence of link ID's as required by the recursive logit estimation code, transit paths are routed on the time-dependent GTFS graph in the R5 router. A reference table matched each static link in the generated transit network to the observed path in the diachronic R5 network. The separate stages of a trip were connected by searching for the transit transfer, or multimodal transfer links that connect the last and first links of sub sequential stages. 
Intermodal trips in the study area are mainly transit paths with access and egress by foot. There are only 12 bike as a main mode trips that also include a transit stage. This is not surprising, given the potential pitfalls of surveys when collecting information on intermodal trips (Clifton and Muhs, 2012) and the fact that intermodal travel - in a strict sense - accounts for an extremely small percentage of trips nationwide, making it difficult to capture sufficient observations for a consistent model estimation in the study area. Trips combining car and transit, or bike and transit, are also rather difficult to observe within the central area of Zurich, where the short trip distances make such mode combinations unattractive.

\section{Recursive logit model estimation}

\subsection{Model specifications}

Two different models are estimated using different observations and network subsets. A first model (M1) is estimated with intermodal trips - in a broad definition - allowing for transit as a main mode and access and egress by walking. This model uses a subset of the network consisting of the transit, as well as walking network and aims at exploring the suitability of the recursive logit model to model intermodal trips. A second model (M2) includes unimodal trips by walk, bike and car to evaluate the ability of the model to estimate mode choice trade-offs for Zurich. The full multimodal network is used for this estimation. Specifications of instantaneous link utilities for each model are given below. To be representative of a path utility, attributes used in the utility function must be link-additive (Fosgerau et al., 2013). Following Zimmermann et al. (2018), we interact mode-specific dummies with the only linkadditive attribute in the network: travel time. Dummies of attributes specific to transit trips, headway and transfers, are only used in the transit model (M1) because they cannot be added to the path utility of a unimodal path. Doing so would lead to a biased estimate of the parameter, depending on the number of times a link containing the attribute is included in a path.

$$
\begin{aligned}
& \begin{array}{c}
U_{M 1}=\beta_{\text {LinkConstant }}+\beta_{\text {TransferMultimodal }} \cdot \delta_{\text {TransferMultimodal }}+\beta_{\text {TransferTransit }} \cdot \delta_{\text {TransferTransit }} \\
+\left(\beta_{\text {TravelTime }}+\beta_{\text {Tram }} \cdot \delta_{\text {Tram }}+\beta_{\text {Bus }} \cdot \delta_{\text {Bus }}+\beta_{H R a i l} \cdot \delta_{H R a i l}+\beta_{H 11} \cdot \delta_{H 11}+\beta_{H 16}\right. \\
\cdot \\
\left.\delta_{H 16}\right) \text { TravelTime }
\end{array} \\
& \begin{array}{l}
U_{M 2}=\beta_{\text {LinkConstant }}+\left(\beta_{\text {TravelTime }}+\beta_{\text {Tram }} \cdot \delta_{\text {Tram }}+\beta_{\text {Bus }} \cdot \delta_{\text {Bus }}+\beta_{H \text { Rail }} \cdot \delta_{H R a i l}+\beta_{W B i k e} \cdot \delta_{\text {Bike }}\right. \\
\left.+\beta_{\text {Car }} \cdot \delta_{\text {Car }}\right) \text { TravelTime }
\end{array}
\end{aligned}
$$

Where:

$\beta$ is the parameter to be estimated

$\delta$ is a dummy indicating if a link belongs to the subscripted category. $H 11$ is 1 if the transit link has a headway below 11 minutes, $H 16$ for transit links with headway between 11 and 16 minutes.

$L C$ is a link constant

TravelTime is the link travel time 
Heavy rail is a category aggregating commuter trains, long-distance and interregional trains. In Zurich, they are all operated by the Swiss Federal Railways, share the same infrastructure and have the same pricing system as all other public transport modes (fares are based on zones). The link-constant represents the disutility of passing a link. For transit links, it can be interpreted as the disutility of each service stop; for individual modes it represents the crossing of an intersection. For transfer links, it is the disutility of transferring. Since the link constant does not represent a trade-off - it has the same value for every link - its t-test value increases with rising numbers of observations. As small links are present in the network, resulting in small attribute values which can prevent the I-M matrix from being invertible, this parameter is needed to assure the numerical feasibility of the model.

\subsection{Results}

The models were estimated on the ETH Euler cluster ${ }^{3}$ because of memory requirements of up to $80 \mathrm{~GB}$ necessary to estimate the models. Different model specifications were tested, but we present only the results of the best-fitting models (Table 5). Following Zimmermann et al. (2018), we calculate in-vehicle time parameters by adding the $\beta_{\text {TravelTime }}$ estimate to the respective mode-specific dummy parameter estimate. In the model M1, the estimate for access/egress is therefore the travel time parameter itself, since there is no explicit dummy for access/egress links in this model. In the model M2 we do not include a dummy for walking nor for transfers, and walking is the reference parameter for the parameter estimates in these models.

Results from model M1 show that rail-based modes do have a bonus in public perception. Shorter headways have, as expected, a positive impact on travel utility. The similar value of the headway parameters shows that this impact is moderate, though. A reasonable explanation for this finding is a high reliability on timetables and service stability. In fact, transit riders in Zurich do arrive at stations near scheduled departure times, even for very short headways (Luethi et al., 2007), thus rather basing their journey on published schedules than on service frequencies.

\footnotetext{
${ }^{3}$ https://scicomp.ethz.ch/wiki/Euler
} 


\begin{tabular}{|c|c|c|c|c|c|c|}
\hline & \multicolumn{3}{|c|}{ Transit (M1) } & \multicolumn{3}{|c|}{ All modes (M2) } \\
\hline & Estimate & t-test & & Estimate & t-test & \\
\hline$\beta_{\text {LinkConstant }}$ & -2.93 & -46.28 & $* * *$ & -3.10 & -2199.95 & $* * *$ \\
\hline$\beta_{\text {TransferTransit }}$ & -3.89 & -17.78 & $* * *$ & & & \\
\hline$\beta_{\text {TransferMultimodal }}$ & -13.21 & -15.15 & $* * *$ & & & \\
\hline$\beta_{\text {Bike }}$ & & & & 4.18 & 12.62 & $* * *$ \\
\hline$\beta_{C a r}$ & & & & 5.47 & 16.53 & $* * *$ \\
\hline$\beta_{\text {Bus }}$ & -0.30 & -7.55 & $* * *$ & 1.30 & 4.74 & $* * *$ \\
\hline$\beta_{\text {Tram }}$ & -0.05 & -1.14 & & 2.00 & 6.60 & $* * *$ \\
\hline$\beta_{\text {HRail }}$ & -0.01 & -0.68 & & -0.62 & -6.16 & $* * *$ \\
\hline$\beta_{\text {TravelTime }}$ & -0.07 & -4.75 & $* * *$ & -2.96 & -8.91 & $* * *$ \\
\hline$\beta_{H 11}$ & -0.21 & -8.37 & $* * *$ & & & \\
\hline$\beta_{H 16}$ & -0.23 & -7.10 & $* * *$ & & & \\
\hline \multicolumn{7}{|c|}{ derived from above for interpretation } \\
\hline In-Vehicle Time Bus & -0.37 & -8.72 & $* * *$ & -1.66 & -3.85 & $* * *$ \\
\hline In-Vehicle Time Tram & -0.12 & -2.65 & $* *$ & -0.95 & -2.12 & $* *$ \\
\hline In-Vehicle Time Heavy Rail & -0.08 & -133.53 & $* * *$ & -3.58 & -10.32 & $* * *$ \\
\hline Access/Egress Travel Time & -0.07 & -1.47 & & & & \\
\hline Bike Travel Time & & & & 1.22 & 2.61 & $* *$ \\
\hline Car Travel Time & & & & 2.51 & 5.36 & $* * *$ \\
\hline Avg. Log Likelihood (final) & -19.75 & & & -106.27 & & \\
\hline Observations & 1197 & & & 5806 & & \\
\hline Network size (links) & 69135 & & & 127873 & & \\
\hline Estimation time $(\mathrm{h})$ & 19 & & & 96 & & \\
\hline
\end{tabular}

Sign. codes: $0 * * * 0.001 * * 0.01 * 0.05$

All estimated time parameters are in minutes

The travel time ratios in model M1 are also found in other studies on the behaviour of transit riders. Scherer (2011) shows that, although being perceived similarly by transit riders, users prefer trams due to their higher level of comfort. Anderson et al. (2017) find the same pattern in a study on the route choice of transit riders in Copenhagen, as do Zimmermann et al. (2018) on the route choice of bus and tram riders in Zurich. Studies focusing on the value of travel time savings, which also include individual modes (car and bike) from Fosgerau et al. (2017) in Denmark and Weis et al. (2017) in Switzerland, find different patterns of travel time parameters. Model estimates by Weis et al. (2017) and Fosgerau et al. (2007), as well as most mode choice model estimations, are also largely based on SP data. Montini et al. (2017), 
estimate mode and route choice models for Zurich based on RP data as well and find similar ratios to those in this paper, suggesting that the type of data used for model estimation has a significant influence on parameter estimates. Another difference is the defined study region for these two studies - namely, all travel within a country - while we restrict ourselves to an urban agglomeration.

The higher value for access/egress travel time in contrast to in-vehicle times in model M1 might seem counterintuitive at first, since they seem to contradict findings in literature (Weis et al., 2017; Iseki et al., 2016; Anderson et al., 2016; Arentze et al., 2013; Fosgerau et al., 2007; Hoongedoorn-Lanser, 2005). In these studies, access and egress times are rated worse than invehicle times. The negative effect of accessing or egressing transit is captured by another parameter in this model. The $\beta_{\text {TransferMultimodal, }}$ which represents a transfer from the street network to the transit network, makes a significant contribution to intermodal travel disutility. The recursive logit model thus presents a means of splitting the access/egress element into its parts and differentiating transfers from individual modes to transit and from transit to transit. Such explicit differentiation between both forms of transfer has not been modelled before, although Hoongedoorn-Lanser (2005) calls for such a representation for modelling transfers in intermodal trips. As discussed by her, a transfer into a transit stage from an individual mode is expected to have a higher disutility than transferring between transit stages. This is corroborated by model M1. As discussed by Wardman et al. (2001), this might be related to the fact that by providing real-time information on connections or just reliable transfers, the transit agency reduces the stress level of such a transfer. Waiting-times are not explicitly modelled here, but are captured by the transfer multimodal dummy; these are known to have a significant negative impact on a transfer between different modes. To foster multimodal trip making and the use of transit in general, transit operators and planners should therefore focus on improving the transfer experience to and from transit services.

While the trade-offs of model M1 are in-line with the reviewed literature, the results from model M2 seem counterintuitive at a first glance. Mode choice literature is almost unanimous in finding values of travel time for car that are equal or lower than transit, while the inverse is true for the parameter values in model M2. It is important to note that, although having positive parameters, variables values (Table 4) show that link utility is always negative. The inverse ratio found here is explained by the lack of an alternative specific constants in our model, which usually captures a great deal of the travel utility. This is not possible here for reasons explained above. Nonetheless, the model does reproduce the expected higher utility of travelling by individual modes, especially by car, when compared to travel by transit. The SP/RP analysis from the microcensus (Weis et al., 2017) has differing results regarding the trade-offs between bike and walk, depending on the chosen model specification, but the parameter values for bike and walk are always between the value of transit in-vehicle times and car travel times, a finding corroborated by the estimates in model M2.

Although the ratio between tram and bus stays similar among the two models, the ratio between heavy rail and street bound transit becomes inverted in model M2. The lack of an explicit representation of transfers in this model and the high disutility produced by multimodal 
transfers in model M1 suggest that in-vehicle time parameters for transit are also capturing transfer disutilities. The lower value of the heavy rail in-vehicle time parameter thus suggests that transferring to a heavy rail station is much more burdensome than to street bound transit modes, which are integrated in the urban fabric (Iseki et al., 2006). Accessing heavy rail stations require longer access times and distances and often do not allow for barrier-free access. The in-vehicle time parameters in this model are therefore capturing more travel burdens than the travel with the mode itself.

\section{Discussion}

This paper focused on intermodal trip making and modelling on a multimodal network with the recursive logit model.

\subsection{Intermodal trip making}

Socioeconomic determinants for intermodal behaviour are in accordance with findings in the reviewed literature. As in other studies, Swiss intermodal travellers can be characterized as urban, young, female, well-educated and childless. An important finding: ownership of transit mobility tools (subscriptions that allow free use of public transport) is even more important than transport supply on a daily level. Any policy aiming at increasing intermodal travel behaviour should therefore aim to expand the ownership of such subscriptions and therefore transit supply. The remaining regression parameters corroborate findings from the Netherlands and Germany, showing that in western Europe - at least - intermodal behaviour is driven by the same factors.

\subsection{Recursive logit}

This paper is the first to estimate a recursive logit model on a large scale and the first to make use of this model to estimate travel demand on a multimodal network. The main finding from these estimations is that the recursive logit model can consistently estimate trade-offs between segments of intermodal trips (model M1), as well as trade-offs between different modes in a multimodal network (model M2). Because it only requires a multimodal network and path observations matched to it as inputs, it is certainly a candidate for an integrated transport modelling solution in an era where the role of GPS tracking based data collection is increasing. Data like these allow for direct path observations on urban networks. Because only a network in the form of an edge-list is needed to represent alternatives, the need for path sampling is eliminated, removing the choice-set sampling bias in the parameter estimates. This allows for a simple and straightforward estimation of travel demand parameters in a multimodal network, independent of the trip chain. 


\subsubsection{Limitations}

This paper's main contribution is demonstrating the feasibility of a multi-modal recursive logit route choice model; however, it does not account for several variables that should significantly improve its explanation of travel demand. On the demand-side, these shortcomings include lack of travel purpose and socioeconomic variables in the model estimation, which are known to influence travel time values when interacted with them. On the supply-side, the type of station should be included, as suggested by the results in model M2. Further, this paper did not test the inclusion of the link-size attribute nor a nested recursive logit formulation, both of which are known to improve the quality of recursive logit estimations (Mai et al., 2015). These remain challenging though, since both formulations would require up to ten times the time needed to estimate the models in this paper.

\subsubsection{Outlook}

More work on network construction and matching of observations to the network can further simplify it and decrease computation expense of model estimations. Instead of representing individual platforms of each train station, for example, these can be aggregated into one, reducing the number of links in the transit network. For the street network, algorithms should be created to reduce complex intersections, such as roundabouts, to a single node with outgoing links. With such network simplifications, estimation of models on larger networks would become feasible. By combining a simplified urban network with a hub-and-spoke network for interurban connections, a multimodal recursive logit route choice model can be estimated to model travel demand for Switzerland, for example.

A main field of future research is the application of the parameter estimates for multimodal traffic assignment. The use of recursive logit parameters for stochastic assignment allow the modelling of network flows which are consistent with real mode and route choice behavior. This way, we expect that flows on new transport infrastructures, as well as impacts of changes in transport supply, policy or land-use on a multimodal transport network can be predicted with higher accuracy. In this context, the embedding of multimodal transfer station characteristics - as we showed, the most crucial element of intermodal trip making - in the model, enables planners to evaluate the effects of improvements in existing stations and the impact of new ones on network flows and intermodal travel.

\section{Acknowledgements}

We thank Joseph Molloy for providing the adapted Graphhopper routing algorithm. 


\section{References}

Abkowitz, M.D.S., R. Waksam, L. Englisher, N. Wilson (1978) Transit Service Reliability, in TSC Urban and Regional Research Series 1978, U.S. Department of Transportation .

Anderson, M. K., O. A. Nielsen and C. G. Prato (2017) Intermodal route choice models of public transport passengers in the Greater Copenhagen Area, European Journal of Transportation and Logistics, 6, 221-245.

Arentze, T. A. and E. J. E. Molin (2013) Travelers' preferences in intermodal networks: Design and results of a comprehensive series of choice experiments, Transportation Research Part A, 58, 15-28.

Beck, M. J., Hess, S., Ojeda Cabral, M., Dubernet, I. (2017) Valuing travel time savings: A case of short-term or long term choices? Transportation Research Part E, 100, 133143.

Becker, H., A. Loder, B. Schmid and K. W. Axhausen (2017) Modeling car-sharing membership as a mobility tool: A multivariate Probit approach with latent variables, Travel Behaviour and Society, 8, 26-36.

Berlin (2017) Entwurf des Berliner Mobilitätsgesetzes zur Vorlage beim Berliner Senat. Senatsverwaltung für Umwelt, Verkehr und Klimaschutz, Berlin.

BFS (2018) Microrecensement mobilité et transports 2015: Rapport méthodologique: plan d'échantillonage, taux de response et ponderation, Bundesamt für Statistik, Neuchâtel.

BFS and ARE (2017) Verkehrsverhalten der Bevölkerung - Ergebnisse des Mikrozensus Mobilität und Verkehr 2015, Bundesamt für Statistik and Bundesamt für Raumentwicklung, Neuchâtel and Bern.

Blumenberg, E. and G. Pierce (2013) Intermodal travel and the poor: evidence from the 2009 National Household Travel Survey, Transportation Letters, 6 (1), 36-45.

Bovy P. H. L. (2009) On Modelling Route Choice Sets in Transportation Networks: A Synthesis, Transportation Reviews, 29 (1), 43-68.

Bösch, P., K. Müller and F. Ciari (2016) The IVT 2015 Baseline Scenario, Paper presentation 16th Swiss Transport Research Conference, Ascona, May 2016.

Chlond, B. (2013) Multimodalität und Intermodalität, in K. J. Beckmann, A. Klein-Hitpaß (eds.), Nicht weniger unterwegs, sondern intelligenter? Neue Mobilitätskonzepte, 271-293, Deutsches Institut für Urbanistik, Berlin. 
Clauss, T. and S. Döppe (2016) Why do urban travellers select intermodal travel options: A repertory grid analysis, Transportation Research Part A, 93, 93-116.

Clifton, K. and C. D. Muhs (2012) Capturing and Representing Intermodal Trips in Travel Surveys, Transportation Research Record, 2285, 74-83.

Conveyal R5 (2017) https://github.com/conveyal/r5.

Diaz Olvera, L., A. Guézéré, D. Plat and P. Pochet (2014) Intermodality in a context of poor transport integration: the case of Sub-Saharan African cities, Proceedings of the Transport Research Arena 2014, 1-10, Institut Francais des Sciences et Technologies des Transport de l'aménagement et des Réseaux, Paris.

Eluru, N., V. Chakour, A.M. El-Geneidy (2012) Travel mode choice and transit route choice behavior in Montreal: insights from McGill University members commute patterns, Public Transport, 4 (2) 129-149.

Fiorenzo-Catalano, M. S. (2007) Choice Set Generation in Multi-Modal Transportation Networks, Doctoral Thesis, Delft University of Technology.

Franke, S. (2004) Die „,neuen Intermodalen“ Bedingungen eines intermodalen Verkehrsverhaltens, Internationales Verkehrswesen, 56 (3), 105-106.

Frejinger, E., M. Bierlaire and M. Ben-Akiva (2009) Sampling of alternatives for route choice modelling, Transportation Research Part B, 43 (10), 984-994.

Fosgerau M., K. Hjorth, S. V. Lyk-Jensen (2007) The Danish value of time study, Danish Transport Research Institute, Results for experiment 1, Kopenhagen.

Fosgerau, M., E. Frejinger and A. Karlström (2013) A link based network route choice model with unrestricted choice set, Transportation Research Part B, 56, 70-80.

Gallotti, R. and M. Barthelemy (2014) Anatomy and efficiency of urban intermodal mobility, Scientific Reports, 4, 6911.

Gallotti, R., M. A. Porter and M. Barthelemy (2016) Lost in transportation: Information measures and cognitive limits in multilayer navigation, Science Advances, 2.

Graphhopper (2017) https://github.com/graphhopper/graphhopper

Groth, S. (2016) Intermodal divide - Zum sozialen Ungleichgewicht materieller Verkehrsmitteloptionen, Internationales Verkehrswesen, 68 (1), 66-69. 
Guo, Z. and N. H.M. Wilson (2004) Assessment of the Transfer Penalty for Transit Trips: A GIS based Disaggregate Modeling Approach, Transportation Research Record, 1872, $10-18$

Heinen, E. and K. Chatterjee (2015) The same mode again? An exploration of mode choice variability in Great Britain using the National Travel Survey, Transportation Research Part A, 78, 266-282.

Hoongedoorn-Lanser, S. (2005) Modelling Travel Behaviour in Multimodal Networks, Doctoral Thesis, Delft University of Technology.

Iseki, H., B. D. Taylor and M. Miller (2006) The effects of out-of-vehicle time on travel behaviour: Implications for transit transfer, Deliverable 1 for the project Tool Development to Evaluate the Performance of Intermodal Connectivity (EPIC) to Improve Public Transportation, University of California, Los Angeles.

Jarass, J. and Oostendorp, R. (2017) Intermodal, urban, mobil - Charackterisierung intermodaler Wege und Nutzer am Beispiel Berlin, Raumforschung und Raumordnung, 75, 355-369.

Kimpel, T. J., J. G. Strathman and K. Dueker (2000) Time Point-Level Analysis of Passenger Demand and Transit Service Reliability, Center for Urban Studies Publications and Reports, Paper 7.

Klinger, T. (2017) Moving from unimodality to intermodality: Changes in mode choice of new residents, Transportation Research Part A, 104, 221-237.

Krygsman, S. (2004) Activity and Travel Choices in Intermodal Public Transport Systems, Doctoral Thesis, Utrecht University, Utrecht.

Krygsman, S. and M. Dijst (2001) Intermodal Trips in the Netherlands: Microlevel Individual Attributes and Residential Context, Transportation Research Record, 1753, 11-19.

Kuhnimhof, T., J. Armoogum, R. Buehler, J. Dargay, J. M. Denstadli and T. Yamamoto (2012) Men Shape a Downward Trend in Car Use among Young Adults-Evidence from Six Industrialized Countries, Transport Reviews, 32 (6), 761-779.

Levinson D. and S. Zhu (2013) A portfolio theory of route choice, Transportation Research Part C, 35, $232-243$.

Lima A., R. Stanojevic, D. Papagiannaki, P. Rodriguez and M. C. Gonzalez (2016) Understanding individual routing behaviour, Journal of the Royal Society Interface, 13 (116). 
Luethi, M., U. A. Weidmann and A. Nash (2007) Passenger arrival rates at public transport stations, paper presentated at the 86th Annual Meeting of the Transportation Research Board, Washington D.C., January 2007.

Mai, T., M. Fosgerau, and E. Frejinger (2015) A nested recursive logit model for route choice analysis, Transportation Research Part B, 75, 100-112.

Miramontes, M., M. Pfertner, H. S. Rayaprolu, M. Schreiner, G. Wulfhorst (2017) Impacts of an intermodal mobility service on travel behaviour and preferences: user insights from Munich's first mobility station, Transportation, 44 (6), 1325-1342.

Molin, E., P. Mokhtarian, M. Kroesen (2016) Multimodal travel groups and attitudes: A latent class cluster analysis of Dutch travellers, Transportation Research Part A, 83, 14-29.

Molloy, J., C. Tchervenkov and K. W. Axhausen (2017) Estimating the externalities of a sustainable mobility platform using GPS traces, Paper presentation mobil.TUM Conference 2018, Munich, June 2018.

Montini, L., C. Antoniou and K. W. Axhausen (2017) Route and mode choice using GPS data, Paper presentation 96th Annual Meeting of the Transportation Research Board, Washington D.C., January 2017.

Munich (2018) Intermodale Mobilität: Optimierung des öffentlichen Verkehrs in München. https://www.swm.de/privatkunden/m-mobilitaet/mvg/intermodale-mobilitaet.html

Ojeda-Cabral, M., S. Hess, R. Batley (2018) Understanding valuation of travel time changes: are preferences different under different stated choice design settings? Transportation, $45,1-21$.

Olafsson, A. S., T. S. Nielsen, T. A. Carstensen (2016) Cycling in intermodal transport behaviours: exploring modality styles in the Danish population, Journal of Transport Geography, 52, 123-130.

Prato, C. G. (2009). Route choice modeling: Past, present and future research directions. Journal of Choice Modelling, 2 (1), 65-100.

Polk, M. (2004) The influence of gender on daily car use and on willingness to reduce car use in Sweden, Journal of Transport Geography, 12 (3), 185-195

Rieser-Schüssler, N., M. Rieser, L. Montini and K.W. Axhausen (2014) Exploring choice set generation approaches for public transport connection choices, Arbeitsberichte Verkehrs- und Raumplanung, 1023, IVT, ETH Zurich, Zurich. 
Rode, P. and N. F. da Cruz (2018) Governing urban accessibility: moving beyond transport and mobility, Applied Mobilities, 3 (1), 8-33.

Rode, P., C. Hoffmann, J. Kandt, A. Gaff and D. Smith (2015) Towards new urban mobility: The case of London and Berlin, LSE Cities, London School of Economics and Political Science and InnoZ, Innovation Centre for Mobility and Societal Change.

Spickermann, A., V. Grienitz and H. A. von der Gracht (2014) Heading towards an intermodal city of the future?: Multi-stakeholder scenarios for urban mobility, Technological Forecasting and Social Change, 89, 201-221.

Stern, E. and D. Leiser (1988) Levels of spatial knowledge and urban travel modeling, Geographical Analysis, 20 (2), 140-155.

Van Nes, R. and P. H. L. Bovy (2004) Intermodal travelling and its impact on urban transit network design, Journal of Advanced Transportation, 38 (3), 225-241.

Wardman, M., J. Hine and S. Stradling (2001) Interchange and travel choice, volume 1, Report for the Scottish Executive by the Institute for Transport Studies at the University of Leeds and the Transport Research Institute at Napier University, Edinburgh.

Weis, C., M. Vrtic, B. Schmid and K. W. Axhausen (2017) Analyse der SP-Befragung 2015 zur Verkehrsmodus- und Routenwahl, Bundesamt für Raumentwicklung (ARE), Bern.

Williams, H. C. W. L. and J. D. Ortuzar (1982) Behavioural theories of dispersion and misspecification of travel demand models, Transportation Research Part B, 16, $167-$ 219.

Yoo, G. S. (2015) Transfer penalty estimation with transit trips from north Korea, KSCE Journal of Civil Engineering, 19 (4), 1108-1116.

Zimmermann, M., T. Mai and E. Frejinger (2017) Bike route choice modelling using GPS data without choice sets of paths, Transportation Research Part C, 75, 183-196.

Zimmermann, M., K. W. Axhausen and E. Frejinger (2018) Multi-modal route choice modeling in a dynamic schedule-based transit network, Paper presentation IATBR, Santa Barbara, July 2018.

Zhang, J., T. Arentze and H. Timmermans (2012) A Intermodal transport network model for advanced traveller information system, Journal of Ubiquitous Systems \& Pervasive Networks, 4 (1), 21-27. 